Gut, 1986, 27, 829-837

\title{
Modulation of intestinal and systemic immune responses to a fed protein antigen, in mice
}

\author{
S STROBEL AND ANNE FERGUSON \\ From the Gastro Intestinal Unit, Western General Hospital, Edinburgh, and University of Edinburgh, \\ Edinburgh
}

SUMmARY Feeding of a protein antigen to normal adult mice results in systemic immunologic hyporesponsiveness (oral tolerance). Local mucosal cell mediated immunity is not usually elicited. The objectives of these experiments were to abrogate the induction of oral tolerance and concomitantly to induce a local mucosal cell mediated immune response in mice; and thereby to establish which facets of intestinal physiology or immunology are relevant to the induction of normal, mainly suppressor immune responses to a fed antigen. Protein antigen (ovalbumin) was fed to animals in whom immune status had been modulated by intraperitoneal injection of $\mathrm{N}$-acetyl-muramyl dipeptide (MDP), by induction of a graft versus host reaction, or naturally, by virtue of immaturity. The induction of oral tolerance was prevented in all treatment groups. In a second series of experiments mice were orally immunised as before, rested for four weeks, and then challenged with ovalbumin in their drinking water for 10 days. Jejunal architecture was not altered by the antigen challenge, but MDP treated and immature animals which had been sensitised to ovalbumin and later re-exposed to the same antigen had significantly higher intraepithelial lymphocyte counts than appropriate controls. Factors which may lead to abrogation of oral tolerance and induction of intestinal hypersensitivity are discussed in relation to food allergic diseases in man.

Induction of systemic immunological hyporesponsiveness by the feeding of antigen (oral tolerance) is well documented in animals ${ }^{1-3}$ and probably also occurs in man. Immune responses within the gut associated lymphoid tissues (GALT) have been extensively studied, and the associated cellular events examined by in vitro techniques, ${ }^{5-9}$ but comparatively little is known about intestinal mucosal cell mediated immunity and its regulation in vivo.

There are as yet no methods for direct measurements of a mucosal cell mediated immune response but we ${ }^{10111}$ and others ${ }^{12} 1.3$ have shown that an increased count of intraepithelial lymphocytes, elongation of the crypts, increase in crypt cell proliferation, and a reduction in villus length, provide indirect evidence of a mucosal cell mediated immune response in experimental animals ${ }^{14}$ and man. ${ }^{15}$ Of these features, the intraepithelial lymphocyte count is the most sensitive index. ${ }^{16}$

Address for correspondence: Dr Stephan Strobel. Department of Immu nology. Institute of (hild Health. 30. Guilford Strect. I.ondon. WCIN IEH

Received for publication 17 October 198.5
In our earlier experiments on the induction of immune responses by the feeding of antigen, we found that modulation of the immune status of mice (by cyclophosphamide treatment) before antigen administration partially reversed oral tolerance ${ }^{17}$ and induced a state of local cell mediated immunity. ${ }^{1+}$ These results led us to hypothesise that abrogation or breakdown of the normal gut immune responses such as oral tolerance may be the underlying pathogenesis of food allergic diseases, including the food protein sensitive enteropathies. In order to test this hypothesis in other states of aberrant immunity, we have examined immune responses to a fed protein antigen, ovalbumin, in animals immunomodulated by means of a graft versus host reaction; by injection of the synthetic adjuvant $\mathrm{N}$-acetyl-muramyl dipeptide (MDP); or in animals which are naturally immunologically inexperienced by virtue of their age. We here present evidence that immunomodulation prevented the induction of oral tolerance in mice, and was associated with a rise in intraepithelial lymphocyte counts on antigen re-exposure, suggesting active immunisation for mucosal cell mediated immunity. 
Table Experimental protocols

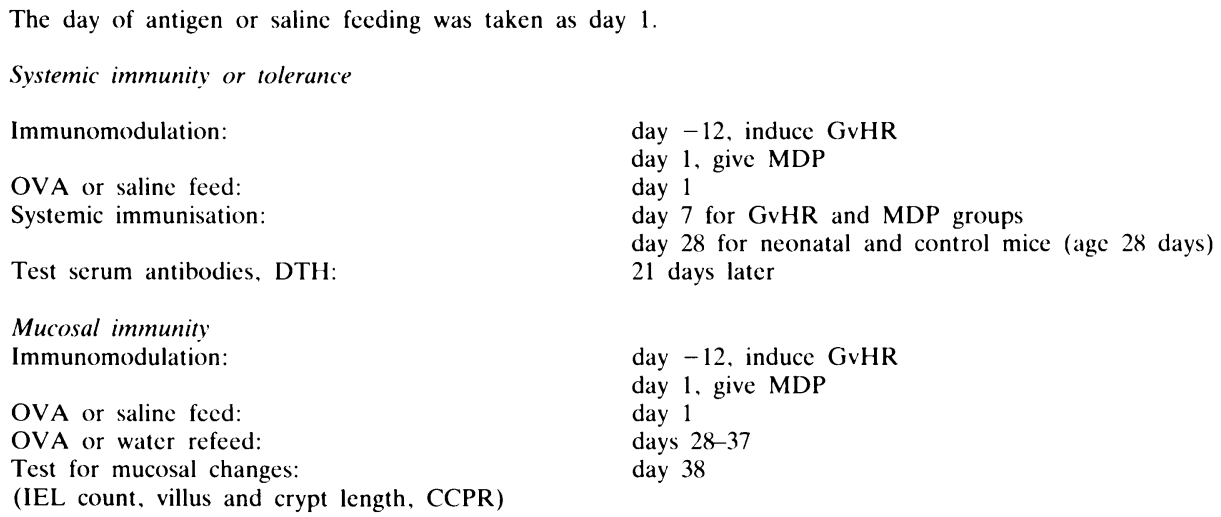

Immunomodulation:

OVA or saline feed:

Systemic immunisation:

Test serum antibodies, DTH:

Mucosal immunity

Immunomodulation:

OVA or saline feed:

OVA or water refeed:

Test for mucosal changes:

(IEL count, villus and crypt length, CCPR)

day -12 , induce GvHR

day 1 , give MDP

day 1

day 7 for GvHR and MDP groups

day 28 for neonatal and control mice (age 28 days)

21 days later

day -12 , induce GvHR

day 1 , give MDP

day 1

days $28-37$

day 38

GvHR $=$ graft versus host reaction. $M D P=N$-acetyl-muramyl dipeptide. $I E L=$ intraepithelial lymphocytes

$\mathrm{OVA}=$ ovalbumin. $\mathrm{DTH}=$ delayed type hypersensitivity. $\mathrm{CCPR}=$ crypt cell proliferation rate.

\section{Methods}

EXPERIMENTAL PROTOCOL

The Table provides a general outline of the protocols used for the assessment of systemic and local immunity.

\section{ANIMALS}

Female $\left(\mathrm{C} 57 \mathrm{BL} 6 / \mathrm{JxDBA}_{2}\right) \mathrm{F}_{1}\left(\mathrm{BDF}_{1}\right)$, and BALB/c mice, of both sexes and aged six to 10 weeks, were used. There were six to 10 mice per group. The mice were bred in the Animal Unit of the Western General Hospital, Edinburgh. Neonatal animals were fed antigen 18-36 hours after birth.

\section{ANTIGEN}

Ovalbumin (Sigma Chemical Company, Poole, UK), five times crystalised, was dissolved at $100 \mathrm{mg} / \mathrm{ml}$ in $0.15 \mathrm{M}$ saline. The dose used in adult mice and in neonates was $1 \mathrm{mg} / \mathrm{g}$ bodyweight.

FEEDING TECHNIQUE

Adult animals were intubated with a 19 gauge stainless steel feeding tube, neonatal animals with 00 flexible nylon intravenous tubing (Portex) attached to a 26 gauge needle stock. Full details have been published elsewhere. ${ }^{18}$

SYSTEMIC IMMUNISATION

Mice were immunised with $100 \mu \mathrm{g}$ ovalbumin in complete Freunds adjuvant into the left hind footpad at seven days (adults) or four weeks (neonatal experiments) after the initial sensitising feed. Systemic immunity was measured three weeks after immunisation.

\section{MEASUREMENT OF SYSTEMIC IMMUNITY Antibody responses}

Serum IgG antibody was measured by using an ELISA test. ${ }^{18}$ Microtitre plates were coated with $0.1 \mathrm{mg}$ ovalbumin dissolved in $0.03 \mathrm{M}$ carbonate buffer $\mathrm{pH} 9.6$ for two hours at $37^{\circ} \mathrm{C}$. Sera were added at a dilution of $1 / 100$ (five hours at room temperature) and alkaline phosphatase conjugated goat anti-mouse IgG antiserum (Northeast Biomedical) added at a dilution of $1 / 1000$ (16 hours at room temperature). The substrate, p-nitro-phenylphospate (Sigma Chemical) was added at $1 \mathrm{mg} / \mathrm{ml}$ in $10 \%$ diethanolamine buffer $\mathrm{pH} 9.8$ and the colour development monitored at $405 \mathrm{~nm}$ with an automatic microelisa reader (Dynatech Limited). Serum samples were assayed in triplicates, and appropriate control sera were included into each assay to correct for day to day variations. Results are given as individual absorbance readings. Intraassay variation was $5.9 \%$ and interassay variation $10 \cdot 4 \%$.

\section{Systemic delayed type hypersensitivity responses}

Mice were tested for delayed type hypersensitivity by measuring the specific footpad swelling 24 hours after an intradermal injection of $100 \mu \mathrm{g}$ of antigen in $0.05 \mathrm{ml}$ of $0.15 \mathrm{M}$ saline into the plantar side of a non-immunised rear footpad. Measurements were made with microcalipers (POCOTEST-A, Carobronze Limited, UK). Control mice were either immunised with complete Freunds adjuvant and saline and tested with antigen, or were immunised with antigen in complete Freunds adjuvant and were tested with $0.05 \mathrm{ml}$ of ()$\cdot 15 \mathrm{M}$ saline. 
INTESTINAL MORPHOLOGY AND EPITHELIAL CELL KINETICS

Intraepithelial lymphocyte counts

Pieces of jejunum ( $10 \mathrm{~cm}$ beyond the pylorus) were fixed in $10 \%$ buffered ( $\mathrm{pH} \mathrm{7.0)}$ formalin, paraffin embedded, cut at $4 \mu \mathrm{m}$ and stained with haematoxylin and eosin. A differential cell count was made under oil immersion ( $\times 1000$ magnification) of the cells within the epithelium covering the villi and intraepithelial lymphocytes counts were expressed as numbers of intraepithelial lymphocytes/100 epithelial cells.

Villi and crypts

Lengths of villi and crypts, and crypt cell production rates, were measured by the metaphase arrest and microdissection techniques first described by Clarke (1970) and routinely used in our laboratory. ${ }^{1920}$ All groups of animals were given $7.5 \mathrm{mg}$ colchicine (BDH) per kg bodyweight and killed by cervical dislocation at intervals of 20-120 minutes afterwards to allow accumulation of metaphases in intestinal crypts. Pieces of jejunum $(10 \mathrm{~cm}$ beyond the pylorus) were fixed in $75 \%$ ethanol $/ 25 \%$ glacial acetic acid for six hours and then stained in bulk - after acid hydrolysis at $60^{\circ} \mathrm{C}$ - with the modified Feulgen stain (Schiff reagent; Difco).
Villus and crypt lengths are expressed in $\mu \mathrm{m}$ and the crypt cell production rate as the rate of accumulation of metaphases/crypt/hour in a particular experimental group.

\section{IMMUNOMODULATION TREATMENTS}

Fifty micrograms $\mathrm{N}$-acetyl-muramyl-dipeptide (Adjuvant dipeptide, MDP; Sigma) in $0.2 \mathrm{ml}$ of $0.15 \mathrm{M}$ saline was injected intraperitoneally immediately $\left(<1\right.$ minute) before oral intubation of $\mathrm{BDF}_{1}$ mice.

\section{Graft versus host reaction}

A graft versus host reaction was induced 12 days before the antigen feed, by the intraperitoneal injection of $6 \times 10^{7} \mathrm{C} 57 \mathrm{BL} 6 / \mathrm{J}$ spleen cells into $\mathrm{BDF}_{1}$ mice. Controls were injected with $\mathrm{BDF}_{\mathrm{I}}$ spleen cells. Spleen cell suspensions were made with RPMI 1640 medium (Flow Laboratories) and the viability as assessed by $2 \%$ Trypan blue exclusion was greater than $80 \%$. For documentation of graft versus host reaction at the time of feeding. some animals of each experimental group were killed at day 12, their body and spleen weights measured, and Simonsen's spleen index ${ }^{21}$ was calculated (this is obtained by dividing the relative spleen weight (mg/g body weight) in the graft versus host reaction group, by the relative spleen weight in controls).

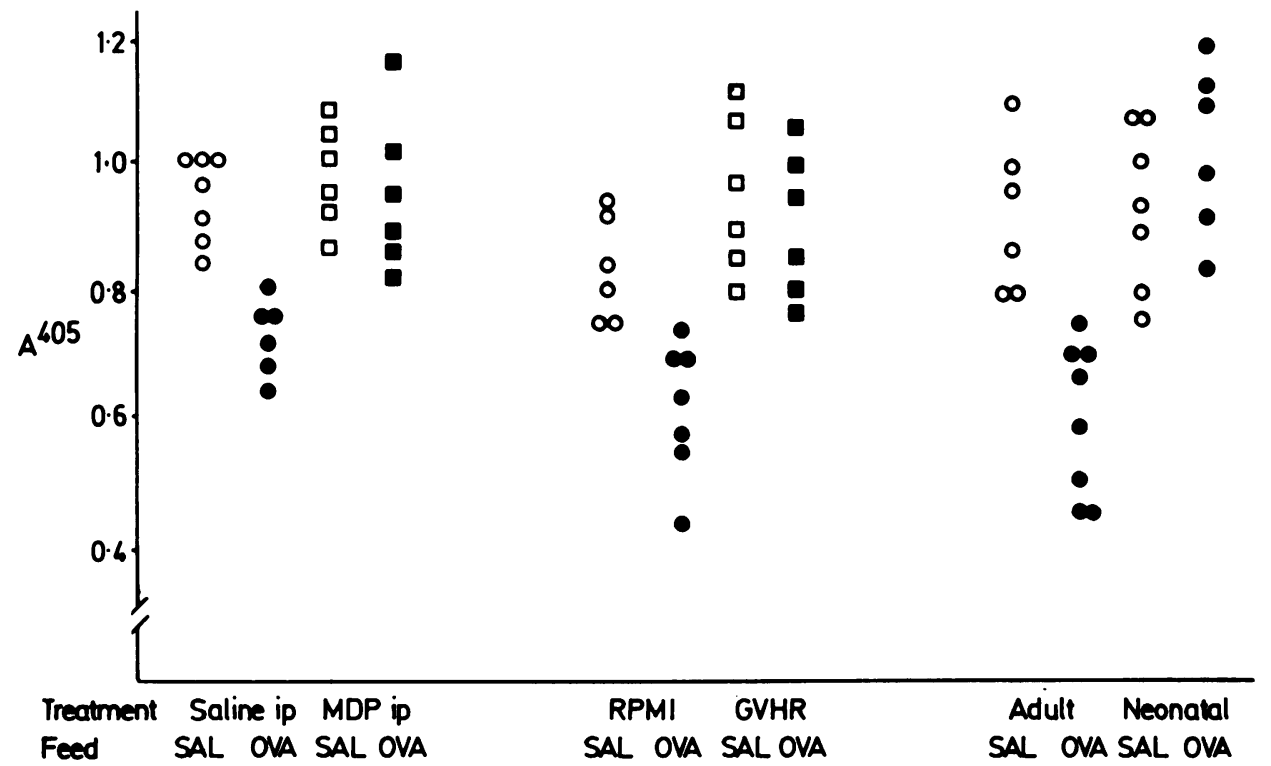

Fig. 1 IgG anti-ovalbumin antibody levels after an ovalbumin feed and systemic immunisation in three experimental groups of mice, with appropriate controls. Left: $50 \mu \mathrm{g} \mathrm{N}$-acetyl-muramyl dipeptide ip. Centre: Graft versus host reaction (12 days before feed) Right: Immaturity (neonatal feed). All control groups demonstrate significant suppression of systemic immunity $(p<0 \cdot 01)$. Immunomodulation with $N$-acetyl-muramyl dipeptide and a graft versus host reaction prevented the induction of tolerance. After neonatal antigen exposure induction of tolerance was also prevented and some animals exhibited signs of priming $(p<0 \cdot 1=N S) . M D P=N$-acetyl-muramyl dipeptide. $G v H R=g r a f t$ versus host reaction. 


\section{Immaturity}

Neonatal BALB/c mice, of both sexes, were fed ovalbumin on the first day after birth (age 18-36 hours) and were kept under normal animal housing conditions thereafter.

EXPERIMENTAL PROTOCOL FOR STUDY OF ORAI. TOI.ERANCE

Adult mice, immunomodulated and controls, were parenterally immunised seven days after the antigen feed. Neonatally fed animals were parenterally immunised at four weeks of age. In all animals blood was collected three weeks later and $\mathrm{IgG}$ anti ovalbumin antibody measured by ELISA. At the same time the footpad swelling test for delayed type hypersensitivity was performed. Wilcoxon's rank sum test was used to compare the results of ELISA tests in the various groups, and the t-test for delayed type hypersensitivity responses. Suppression of antibody and delayed type hypersensitivity responses was calculated thus:

$$
\begin{gathered}
\left(1-\frac{\text { (response in experimental animals) }}{\text { (response in control animals) }}\right) \times 100 \\
=\% \text { suppression }
\end{gathered}
$$

EXPERIMENTAL PROTOCOL FOR MUCOSAL CELI. MEDIATED IMMUNITY

Aill groups of mice were rested for four weeks after the initial sensitising feed, and then challenged for 10 days with $0.1 \mathrm{mg}$ ovalbumin/day in their drinking water. On the 10th day they were given colchicine as described above, killed, and the presence or absence of intestinal cell mediated immunity inferred from intraepithelial lymphocytes counts and mucosal architecture measurements. Crypt cell production rates were calculated by linear regression and analysis of covariance was used to compare the slopes of the best fit curves. The t test was used for comparison of villus and crypt lengths.

\section{Results}

ATTEMPTS TO MODUI.ATE ORAI. TOIERANCE Systemic antibody and delayed type hypersensitivity responses in all of the groups of animals are shown in Figures 1 and 2. For all of the treatment regimes, the relevant, immunologically normal, control groups show significant suppression $(p<() \cdot() 1)$ of systemic immunity to ovalbumin after antigen feeding when compared with saline fed controls - that is, there is oral tolerance.

Intraperitoneal injection of $50 \mathrm{\mu g}$ MDP immediately before an ovalbumin feed totally abro- gated suppression for humoral IgG antibody responses and also reversed tolerance for delayed type hypersensitivity and these responses were not significantly different from those of saline fed, MDP injected control groups (29\% suppression) (Figs 1 and 2).

The successful induction of a graft versus host reaction was confirmed by easily visible splenomegaly in the relevant animals confirmed by a spleen index for the group of 1.74. An ovalbumin feed on day 12 of this semi-allogeneic graft versus host reaction did not induce suppression of systemic immunity, whereas this occurred, as predicted, in medium injected control animals. Again, prevention of oral tolerance was more complete for humoral than for delayed type hypersensitivity responses (Figs 1 and 2).

A unique feature, which we have already described in detail, ${ }^{18}$ is seen when ovalbumin is fed to

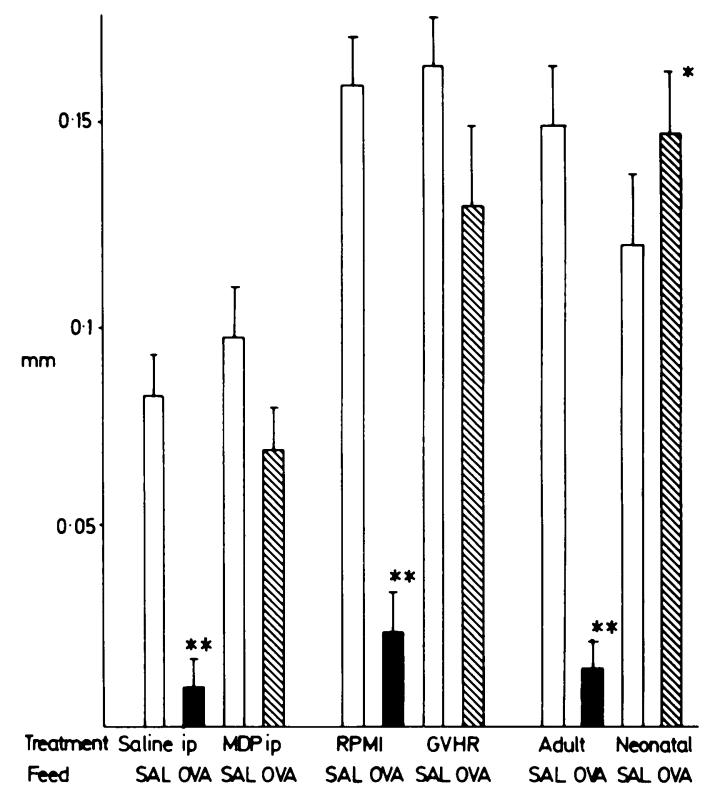

Fig. 2 Systemic delayed type hypersensitivity after an ovalbumin feed and systemic immunisation in three experimental groups of mice, with appropriate controls. Left: $50 \mu \mathrm{g} \mathrm{N}$-acetyl-muramyl dipeptide ip. Centre: Graft versus host reaction (12 days before feed) Right: Immaturity (neonatal feed). All controls exhibit a significant reduction of delayed type hypersensitivity responses $(p<0) \cdot(0)$ after an ovalbumin feed. The slight reduction of delayed type hypersensitivity in the $N$-acetyl-muramyl dipeptide and graft versus host reaction groups was not significant (MDP 29\%; GvHR 20\%). Neonatally fed animals (right) did not show any signs of systemic suppression but demonstrated 25\% enhancemeni (priming) $(p=0) \cdot(05) . O V A=$ ovalbumin. DTH = delayed type hypersensitivity. 
healthy, otherwise untreated neonatal mice. The expected suppression of systemic immunity is prevented for both limbs of the immune system and there is evidence of priming for antibody and delayed type hypersensitivity responses. This does not quite reach statistical significance $36 \%$ enhancement for antibody and $25 \%$ for delayed type hypersensitivity $\mathrm{p}<0 \cdot 1$ ) (Figs 1 and 2 ), but has been present in five further, similar experiments.

\section{INDUCTION OF MUCOSAL CELL MEDIATED} IMMUNITY

Subjective examination of routine histological sections (formalin fixed, haematoxylin and eosin stained $5 \mu \mathrm{m}$ sections) did not reveal abnormalities

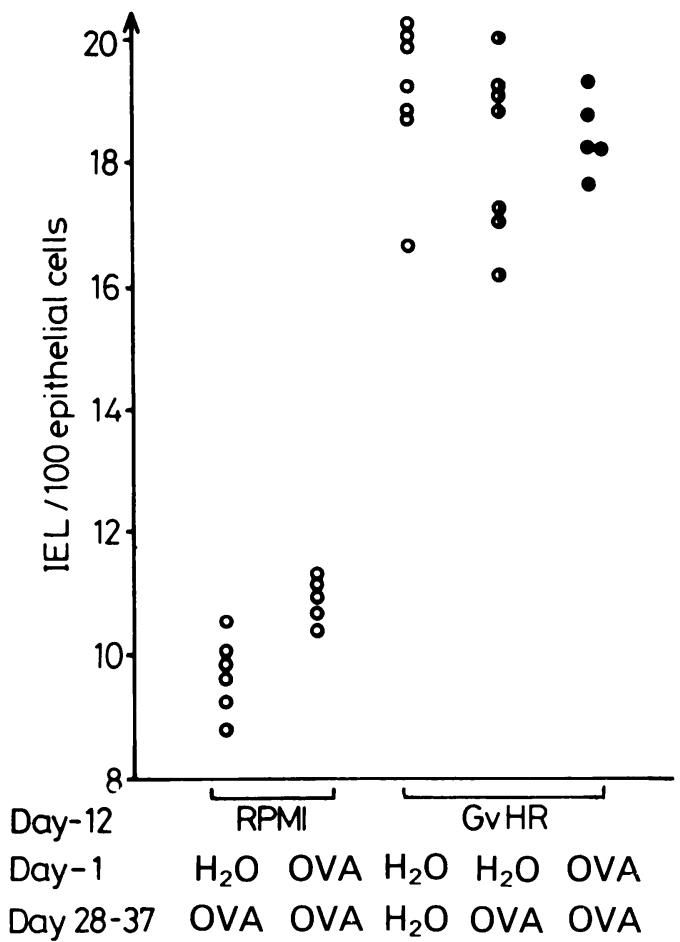

Fig. 3 Graft versus host reaction and induction of local cell mediated immunity to ovalbumin: Intraepithelial lymphocytes. Controls (RPMI injected animals) showed an intraepithelial lymphocyte count of $8 \cdot 5 / 100-11 \cdot 7 / 100$ epithelial cells. Ovalbumin challenge in controls did not further increase intraepithelial lymphocyte counts. All graft versus host reaction groups exhibited an intraepithelial lymphocyte count of 16.2-20.4/100 epithelial cells, regardless of whether the groups were left untreated, challenged only or enterically primed and challenged. The difference in intraepithelial lymphocyte counts between the RPMI groups and graft versus host reaction groups is highly significant $(p<0 \cdot 001)$. IEL=intraepithelial lymphocytes. $R P M I=$ medium injected controls. in any of the three treatment groups. The results of microdissection studies of jejunum from animals in the three immunomodulation studies are summarised in Figures 3, 4, and 5. There were no significant differences from controls in any of the treatment groups. By the time the experiment came to an end the graft versus host reaction mice were at 50 days after induction of the reaction, and, as

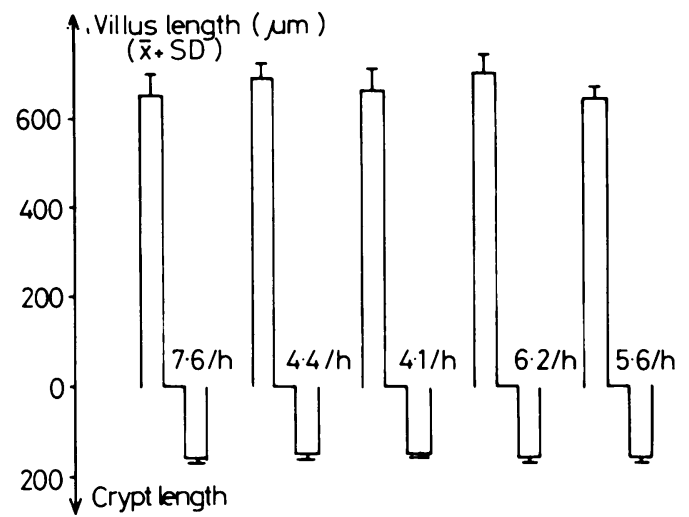

Fig. 4 Graft versus host reaction and induction of local cell mediated immunity to ovalbumin: Gastrointestinal morphology. The graft versus host reaction did not lead to any abnormalities of gastrointestinal morphology at 50 days after induction. Crypt and villus lengths as well as crypt cell production rates were similar in all groups of mice, regardless of the treatment conditions.
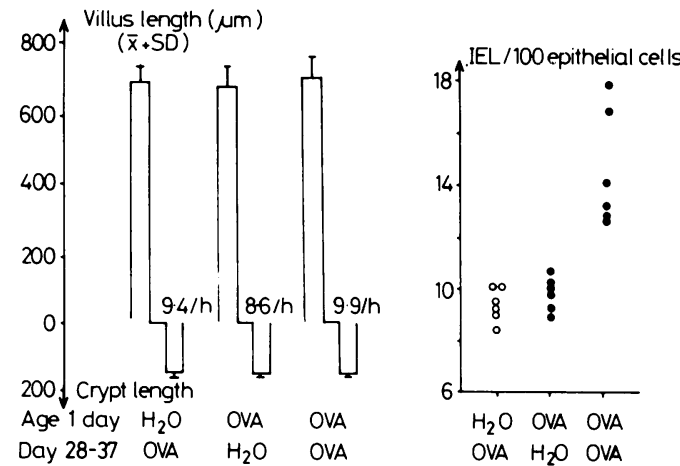

Fig. 5 Gastrointestinal morphology and intraepithelial lymphocyte infiltration after a neonatal ovalbumin feed and challenge. Left: morphology. There were no differences in villus or crypt lengths or crypt cell production rates in any of the treatment groups. Right: Intraepithelial lymphocytes. There is a significant rise in intraepithelial lymphocyte counts in the group of animals which have been fed on day 1 of life and challenged with ovalbumin after 4 weeks $(p<0 \cdot 01)(8 \cdot 2-10 \cdot 6 / 100$ epithelial cells versus $12 \cdot 4-18 \cdot 2 / 100$ epithelial cells). 

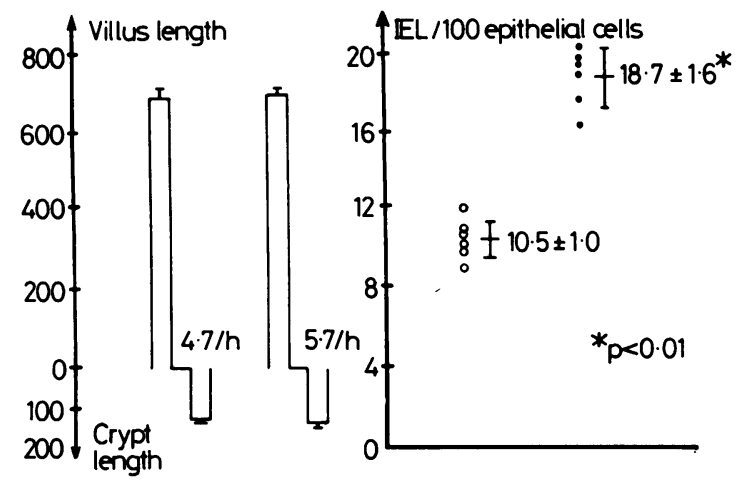

$\begin{array}{lll}\text { Day 1 } & \text { MDP } & \text { MDP } \\ \text { Day 1 } & \text { SAL } & \text { OVA } \\ \text { Day 28-37 } & \text { OVA } & \text { OVA }\end{array}$

$\begin{array}{ll}\text { MDP } & \text { MDP } \\ \text { SAL } & \text { OVA } \\ \text { OVA } & \text { OVA }\end{array}$

$\mathrm{BDF}$, \&

Fig. 6 Gastrointestinal morphology and intraepithelial lymphocyte infiltration after immunomodulation with $N$-acetyl-muramyl dipeptide and enteral sensitisation to ovalbumin. Left: morphology. There was no effect on gastrointestinal morphology as measured by villus and crypt length or crypt cell production rates. Right: intraepithelial lymphocytes. $N$-acetyl-muramyl dipeptide pretreatment and a single ovalbumin feed before an ovalbumin challenge lead to a highly significant increase in intraepithelial lymphocyte counts $(p<0.01)$.

shown in Figure 4, there were no mucosal abnormalities at this time in the graft versus host reaction mice.

Positive findings were obtained in the studies of intraepithelial lymphocyte infiltration of the mucosa. All experimental groups in which prevention of oral tolerance had been achieved by immunomodulation, also had high intraepithelial lymphocyte counts after ovalbumin challenge (Figs 3,5, and 6). Differences between immunomodulated and control groups (all ovalbumin fed and later challenged by a 10 day refeed) were significant at the $p<0.001$ level for MDP and immaturity groups. Mice which had been fed saline on day 12 of a graft versus host reaction still had high intraepithelial lymphocyte counts at 50 days and there was no additional increment in those which had been fed ovalbumin at the same stage of a graft versus host reaction.

\section{Discussion}

When the first encounter with an antigen is via the gut, several different immune responses may evolve, not only in the GALT, but also systematically apart from secretory antibodies, ${ }^{23}$ the general trend is for a down regulation of subsequent immune responses to the antigen concerned - oral tolerance for serum antibody and systemic delayed type hypersensitivity responses, and absence of mucosal delayed type hypersensitivity. It is not yet known if mucosal delayed type hypersensitivity responses are actively suppressed or if there is simply an absence of any immunological effect in terms of induction or suppression.

A considerable body of information has been accrued on factors which influence and induce oral tolerance. ${ }^{1} 61013172425$ The main objectives of the work described in this paper were to examine a range of techniques which are likely to abrogate the state of oral tolerance, and concomitantly to investigate whether mucosal delayed type hypersensitivity can be induced. By three quite different techniques, oral tolerance has been abrogated, and in two of the situations, changes suggestive of intestinal delayed type hypersensitivity were also produced after antigen challenge via the gut.

In earlier work, investigating mechanisms which regulate systemic and local immune responses after feeding, we and others have shown that pretreatment with cyclophosphamide, and oestrogen therapy, lead to partial or complete prevention of oral tolerance and at the same time induce local mucosal immune responses in the small intestinal mucosa, (as measured by a lymphocyte migration technique, and by jejunal crypt hyperplasia and raised intraepithelial lymphocyte counts after antigen refeeding). ${ }^{13} 17$ The mechanisms of immunomodulation differ in these two systems. Cyclophosphamide acts at the $\mathrm{T}$ suppressor cell level whereas oestrogens activate the reticuloendothelial system and increase antigen presenting activity of macrophages. ${ }^{1326}$

In the experiments described in this paper we have disturbed the equilibrium between helper and suppressor cells by using MDP, a substance which acts via macrophage activation in cooperation with $\mathrm{T}$ helper cells. ${ }^{27} 28 \mathrm{~N}$-acetyl-muramyl dipeptide administration can lead to either immunostimulation or immunosuppression, depending on the length of time between administration of MDP and antigen exposure. The mode of action of MDP when given according to the protocol in our work, is immunostimulant, probably via macrophage activation and increased antigen presenting activity (Mowat and Strobel, unpublished). Such an interpretation is in keeping with the data of several authors who have proposed that induction of tolerance by parenteral administration of antigen reflects the function of the reticuloendothelial system. ${ }^{26}$

Features of jejunal histology after a 10 day antigen challenge have been used as indirect indices of mucosal cell mediated immunity in the MDP treated mice, and also in mice of the other immuno- 
modulated groups. In the experiments described above we did not succeed in producing crypt hyperplasia or villus atrophy. As assessed by a significantly increased intraepithelial lymphocyte count, however, positive results, indicative of a cell mediated immune reaction, were obtained. It has been our impression that the small intestine of the mouse is relatively resistant to the induction of villus atrophy. Furthermore, although in some experiments we have managed to produce crypt hyperplasia in association with cell mediated immunity reactions, this has not always been the case. For example cyclophosphamide treatment followed by antigen sensitisation and challenge, led to crypt hyperplasia with intraepithelial lymphocyte infiltrate in some experiments ${ }^{14}$ but in others only an increase in the intraepithelial lymphocyte count was produced. ${ }^{11}$ The phenomena reported in this paper are certainly consistent with local mucosal delayed type hypersensitivity to ovalbumin, but it will be important to repeat the work in rodents which are more susceptible to crypt hyperplasia and villus atrophy, for example rats, or mice within the first two weeks of life.

In MDP treated animals, the induction of a state of delayed type hypersensitivity in the GALT, and absence of oral tolerance, are similar findings to those in oestrogen treated mice..$^{13}$ This indicates that antigen handling by the reticuloendothelial system is relevant to the regulation of mucosal immune responses as well as to systemic immunity.

Mice undergoing a graft versus host reaction have a generalised state of immune stimulation, which includes the presence of active mucosal cell mediated immunity in the small intestinal mucosa. ${ }^{15} 20$ We have published elsewhere the results of experiments on the prevention of oral tolerance induction in mice undergoing a graft versus host reaction, ${ }^{22}$ and there is evidence that this also relates to enhancement of antigen presentation by antigen presenting cells. There are reports that graft versus host reaction animals have suppressed systemic, humoral and cell mediated immune responses ${ }^{30}$ but enhancement of these responses has also been demonstrated during the early phase of a graft versus host reaction. ${ }^{31}$ Thus systemic immune responsiveness after feeding ovalbumin during a graft versus host reaction appears to be dependent on the state of activation or suppression of the immune system. In a separate series of experiments into the time course of this phenomenon we have shown that the capacity for induction of oral tolerance changes during a graft versus host reaction and that this correlates with changes in antigen presenting capacities of a spleen cell population. ${ }^{22}$

We hoped to increase the allogeneically induced mucosal immune responses by induction of an additional cell mediated immune response to the protein antigen ovalbumin. This attempt failed. In the present series of experiments, even on the 50th day after induction of the graft versus host reaction there remained a rise in the mucosal intraepithelial lymphocyte count, which was not further influenced by re-exposure to antigen. It seems likely that in this particular circumstance, in vitro techniques for the demonstration of effector T cells within the GALT would be preferable to in vivo challenge where one is seeking changes in intraepithelial lymphocyte counts or in villus and crypt architecture, additional to those already produced by the injection of the semi-allogeneic cells.

An observation which may have some clinical relevance was that a feed of ovalbumin given to a neonatal mouse has immunological effects which are the opposite of those observed in mature animals. Neonatal feeding of antigen does not lead to systemic hyporesponsiveness. ${ }^{18.32}$ The animals showed signs of enhanced immune reactivity for humoral and cell mediated immune responses. Although this did not reach statistical significance, it has been a consistent observation in many experiments and in a detailed investigation of this phenomenon we found statistically significant priming when antigen was 'fed' to mice the day before birth, by intra amniotic injection. ${ }^{18}$ We now show that mucosal immunity is also influenced by a single feed of ovalbumin on the first day of life, since these animals, if re-exposed to antigen at the age of four weeks, respond with an increased intraepithelial lymphocyte count in the jejunum.

The mechanisms responsible for neonatal systemic priming and mucosal sensitisation are not yet defined. There is dispute as to whether these concern only $\mathrm{B}$ cells, ${ }^{32}$ or whether $\mathrm{T}_{\mathrm{DTH}}$ effector cells are responsible, ${ }^{18}$ and the role of antigen handling by the neonate is yet to be examined. There are several ways, both immunological and digestive, in which immaturity of the gut could contribute to the neonatal patterns of immune responsiveness. Absence of the capacity to digest ovalbumin within the lumen is unlikely to play an important role as systemic hyporesponsiveness in adult animals can be achieved by colonic instillation of antigen. " Although the neonatal intestinal tract and GALT undergo rapid changes during early development, gut 'closure' is not likely to be the mechanism accounting for our observations, at least with regard to oral tolerance or priming, because mice are able to be tolerised on the 14th day of life, several days before gut closure. ${ }^{33}$ Immaturity of immunoregulatory $\mathrm{T}$ cell circuits is, in our view, the most likely explanation. 
Immune responses to fed antigen are complex. Enteral exposure may produce systemic tolerance or less frequently, as described here, immunisation and delayed type hypersensitivity in the intestinal mucosa which may ultimately cause villus atrophy. Several diseases in man, and particularly in infants, are associated, with hypersensitivity or intolerance to food antigens for example, milk protein sensitive enteropathy and infantile colitis. ${ }^{3}{ }^{35}$ Our experiments in animals indicate that oral tolerance requires processing of antigen by the gut and activity of $T$ suppressor cells, and that induction of oral tolerance may fail to occur when there is activation of macrophages with enhanced antigen presentation. Animals thus treated also have intestinal changes after antigen re-exposure which are likely to be caused by a local cell mediated immune response. Further experiments should allow us to establish the mechanism by which the normal down regulation of immune responses fails to occur when neonatal mice are fed protein antigen.

This work was supported by grants from the Medical Research Council, the Deutsche Forschungsgemeinschaft and the National Fund for Research into Crippling Diseases. We acknowledge the skilled technical assistance of Mrs Margaret Gordon, and of the staff of the Animal Unit, Western General Hospital, Edinburgh.

\section{References}

1 Tomasi TB. Oral tolerance. Transplantation 1980); 29: 353-6.

2 Thomas HC, Parrott DMV. The induction of tolerance to a soluble protein antigen by oral administration. Immunology 1974: 27: 631-9.

3 Hanson DG, Vaz NM, Maia L. Hornbrook M. Lynch J. Roy C. Inhibition of specific immune responses by feeding protein antigens. Int Arch Allergy Appl Immunol 1977: 55: 526-32.

4 Korenblatt PE. Rothberg RM. Minden P. Farr RS. Immune responses of human adults after oral and parenteral exposure to bovine serum albumin. $J$ Allergy 1968: 41: 226-35.

5 Ngan J. Kind L. Suppressor T cells for IgE and IgG in Peyer's patches of mice made tolerant by the oral administration of ovalbumin. J Immunol 1976; 120: $861-5$.

6 Kagnoff MF. Elfects of antigen feeding on intestinal and systemic immune responses IV Similarity between the suppressor factor in mice after erythrocyte-lysatte injection and erythrocyte feeding. Gastroenterology 198(); 79: 54-61.

7 Titus RG, Chiller JM. Orally induced tolerance: definition at the cellular level. Int Arch Allergy Appl Immunol 1981: 65: 32.3-6.

8 Richman LK, Chiller JM, Brown WR, Hanson DG, $\mathrm{V}$ az N. Enterically induced immunologic tolerance. I.
Induction of suppressor T-lymphocytes by intragastric administration of soluble proteins. J Immunol 1978; 121: $2429-34$.

9 Mattingly JA, Waksman BH. Immunologic suppression after oral administration of antigen. II. Antigen specific helper and suppressor factors produced by spleen cells of rats fed sheep erythrocytes. $J$ Immunol 198(); 125: 1044-7.

10 Strobel S. Ferguson A. Oral tolerance - induction and modulation. Klin Paediatr 1985; 197: 297-301.

11 Strobel S. Modulation of the immune response to fed antigen in mice. University of Edinburgh: PhD thesis, 1984.

12 Guy-Grand D. Griscelli C. Vassalli P. The mouse gut T lymphocyte, a novel type of T-cell. Nature, origin and traffic in mice in normal and graft-versus-host conditions. J Exp Med 1978; 148: 1661-77.

13 Mowat AMcI, Strobel S. Drummond HE. Ferguson A. Immunological responses to fed protein antigens in mice. I. Reversal of oral tolerance to ovalbumin by cyclophosphamide. Immunology 1982: 45: 105-13.

14 Mowat AMcI. Ferguson A. Hypersensitivity in the small intestinal mucosa. V. Induction of eell mediated immunity to a dictary antigen. Clin Exp Immunol 1981a; 43: 574-82.

15 Slavin RE. Santos GW. The graft-versus-host reaction in man alter bone marrow transplantation: pathology, pathogenesis, clinical features and implications. Clin Immunol Immunopathol 1973; 1: 472-98.

16 Mowat AMcI. Induction and expression of delayed hypersensitivity in the small intestine. University of Edinburgh: PhD Thesis, 1981.

17 Mowat AMcI. Ferguson A. Hypersensitivity in the small intestinal mucosa. V. Induction of eell mediated immunity to a dictary antigen. (lin Exp) Immunol 1981: 43: $574-82$.

18 Strobel S. Ferguson A. Immune responses to fed protein antigens in mice. III. Systemic tolerance or priming is related to the age at which antigen is firsi encountered. Paediatr Res 1984; 18: 588-93.

19) Clarke RM. Mucosal architecture and epithelial cell production rate in the small intestinc of the albino rat. $J$ Anat 1970: 107: 519-29.

20) Mowat AMcI. Ferguson A. Intracpithclial lymphocytc count and crypt hyperplasia measure the mucosal component of the graft-versus-host reaction in mouse small intestine. (jastroenterology 1982; 83: 417-23.

21 Simonsen M. (iralt versus host reactions. Their natural history and applicability as tools of rescarch. Progr Allergy 1962; 6: 349-476.

22 Strobel S. Mowat AMcI. Ferguson A. Abrogation of oral tolerance to ovalbumin and enhanced antigen presentation during a graft-versus-host reaction in mice. Immunology 1985; 56: 57-64.

23 Challacombe SJ, Tomasi TB. Systemic tolerance and secretory immunity after oral immunisation. J Exp Med 1980; 152: 1459-72.

24 MacDonald TT. Immunosuppression caused by antigen feeding. I. Evidence for the activation of a feedback suppressor pathway in the spleens of antigen fed mice. Eur J Immunol 1982; 12: 767-73.

25 Klein JR, Kagnoff MF. Nonspecific recruitment of 
cytotoxic effector cells in the intestinal mucosa of antigen-primed mice. J Exp Med 1984; 160: 1931-6.

26 Yoshikai Y. Miake S, Matsumoto T, Nomoto K. Takeya K. Effect of stimulation and blockade of mononuclear phagocyte system on the induction of suppressor $T$ cells of delayed footpad reaction to SRBC in mice. Immunology 1981; 43: 241-7.

27 Löwy I, Bona C, Chedid L. Target cells for the activity of a synthetic adjuvant: muramyl dipeptide. Cell Immunol 1977; 29: 195-9.

28 Lederer E. Immunostimulation: recent progress in the study of natural and synthetic immunomodulators derived from the bacterial cell wall. In: Fougereau M, Dausset J, eds. Progress in immunology IV. London, New York: Academic Press, 1980: 1194-211.

29 Lukic ML. Cowing C, Leskowitz S. Strain differences in case of tolerance induction to bovine-globulin: dependence on macrophage function. J Immunol 1975; 114: 503-6.

30) Shand FL. Analysis of immunosuppression generated by the graft-versus-host reaction. II. Characterisation of the suppressor cell and its mechanism of action. Immunology 1976; 31: 943-51.

31 Treiber W, Lapp WS. Experimental stimulation of cell-mediated immunity without concomitant stimulation of humoral immunity in graft-versus-host immunosuppressed mice. Transplantation 1976; 21: 391-8.

32 Hanson D. Ontogeny of orally induced tolerance to soluble proteins in mice. I. Priming and tolerance in newborns. J Immunol 1981; 127: 1518-24.

33 Walker WA. Intestinal transport of macromolecules. In: Johnson LR, ed. Physiology of the gastrointestinal tract. New York: Raven Press, 1981: 1271-89.

34 Jenkins HR, Pincott JR, Soothill JF. Milla PJ, Harries JT. Food allergy: the major causes of infantile colitis. Arch Dis Childh 1984; 59: 326-9.

35 Kuitunen P, Visakorpi J, Savilahti E, Pelkonen P. Malabsorption syndrome with cows' milk intolerance. Clinical findings and course in 54 cases. Arch Dis Childh 1975; 50: 351-6. 